\title{
CICLO CRIATIVO DE JOGOS COLABORATIVOS: UM MÉTODO PARA CRIAÇÃO DE JOGOS EDUCATIVOS
}

\author{
J. ANTUNES ${ }^{1, *}$, Z. F QUEIROZ ${ }^{2}$, I. B. R. SANTOS ${ }^{3}$, J. N. LIMA ${ }^{4}$ \\ $1,2,4$ Universidade Federal do Cariri, ${ }^{2}$ Universidade Regional do Cariri, ${ }^{3}$ Insituto Federal do Ceará \\ jeferson.antunes@aluno.ufca.edu.br
}

Submetido 06/08/20 16 - Aceito 12/04/2018

DOI: $10.15628 /$ holos.2018.3298

\section{RESUMO}

Os jogos cooperativos adquiriram importância no campo das metodologias educativas por serem uma linguagem acessível aos jovens, propensa ao trabalho conjuntos e a resolução de problemas que seriam de difícil acesso de forma individual. Essa metodologia proporciona o uso e o aprendizado de habilidades e competências comuns de forma conjunta, valorizando o aprender com o outro, no entanto, a concepção destes jogos ainda é emblemática aos educadores já que o campo de estudos apresenta apenas ações pontuais, sobretudo, quando tratamos de metodologias para criação de jogos. Nosso objetivo, com este estudo, é o de contribuir para o campo metodológico, fornecendo uma ferramenta experimentada pelo LIJC - UFCA, na concepção de jogos cooperativos, que estrutura e inter-relaciona o processo criativo de tomada de decisão. Para tal aporte utilizamos de pesquisa bibliográfica, que permeia tanto o artigo como a metodologia de criação dos jogos, bem como pesquisa exploratória e o relato de experiência da produção da CRIATIVA, metodologia educativa que se estrutura por meio dos jogos cooperativos, produto refinado pelo projeto de extensão e aplicado a participantes de diversas instituições. Este trabalho resultou em uma atividade de caráter lúdico, repleta de significados e estruturada em conceitos como a educação horizontal, o aprender com o outro, o respeito mútuo e a dialógica; onde concluímos que para o sucesso de um método, o aporte conceitual e a experimentação devem estar aliadas, sem esquecer a primazia do sentido de uma educação integral do ser humano.

PALAVRAS-CHAVE: Jogos cooperativos, metodologia, educação, design de jogos, processo criativo.

\section{CREATIVE CYCLE OF COLLABORATIVE GAMES: A METHODOLOGY TO CREATING EDUCATIONAL GAMES.}

\begin{abstract}
Cooperative games have acquired importance in the field of educational methodologies because they are a language accessible to young people, prone to working together and solving problems that would be difficult to access individually. This methodology provides the use and learning of common skills and competences

jointly, valuing learning with others, however, the design of these games is still emblematic of educators since the field of studies presents only specific actions, especially when we deal with methodologies for game creation. Our objective, with this study, is to contribute to the methodological field, providing a tool experimented by the LIJC - UFCA, in the design of cooperative games, that structures and interrelates the creative process of
\end{abstract}

decision making. This research uses a bibliographic study that permeates both article and the metod proposal, this study is exploratories research and a game production experience report, a product refined by the project and applied to participants from different institutions. This work resulted in an activity of a playful character, full of meanings and structured in concepts such as horizontal education, learning with others, mutual respect and dialogical; where we conclude that for the success of a method, the conceptual contribution and experimentation must be allied, without forgetting the primacy of the sense of an integral education of the human being.

KEYWORDS: Cooperative games, metodology, education, game design, creativity . 


\section{INTRODUÇÃO}

O campo de estudos dos jogos cooperativos, associados a educação, nos apresenta possibilidade prática de utilizarmos uma linguagem clara ao jovem, o jogo, para nos envolvermos em ações que possibilitem (re)significar as relações educativas, utilizando esta ferramenta para motivar o uso e a aprendizagem de habilidades e competências que adquirimos ao longo da vida e que seriam de difícil prática em atividades cotidianas.

Pesquisadores (Broto, 2013, Maturana, 2002, Almeida, 2011, Almeida 2010, Boardenave, 1983) apontam o fato de que as atividades cooperativas promovem uma cultura de paz, através da possibilidade de aprender com o outro; possibilitam a interação dialógica, o reconhecimento de múltiplos pontos de vista, o acolhimento, o sentimento de ser parte de um grupo e tomar parte no processo de tomada de decisão; auxiliando a capacidade de resolver problemas que seriam de difícil acepção individualmente que, quando associado ao campo metodológico, fornecem a prática educativa, possibilidade a formação integral do ser humano.

Muito se houve falar sobre a insatisfação do jovem que não vê utilidade prática nos conteúdos aprendidos na escola e na universidade. Fomentar metodologias cooperativas, como o uso de jogos propiciam um ambiente controlado, onde o educador pode, através de métodos e técnicas de design de jogos, conceber uma metodologia estruturada capaz de recriar o ambiente onde os estudantes podem interagir com estes conteúdos, dar-lhes essa "utilidade".

Notamos, nesse campo, um distanciamento dessa atitude interdisciplinar em dialogar com o design, os jogos e o próprio estudo de métodos educativos, e inter-relacionar estes saberes, sejam pelas práticas construídas por esses profissionais em suas carreiras ou mesmo pela facilidade, graças ao advento da internet, de encontrar atividades fabricadas, prontas para o uso, que servem na maioria das vezes de entretenimento, sem fundamentação teórica e metodológica capaz de fomentar momentos lúdicos, inter-relacionando as habilidades e conhecimentos necessários de forma significativa aos participantes.

Existem, contudo, trabalhos pontuais acerca do uso de jogos cooperativos comerciais e atividades recreativas formatadas nesse âmbito, relacionadas as metodologias educativas. Todavia, o que percebemos através de nossas pesquisas é que nos falta um marco metodológico que possa valorizar a experiência da produção de jogos e as metodologias utilizadas durante o processo criativo, estando posicionada nestas questões nossos elementos de estudo.

Este artigo apresenta as experiências dos integrantes do Laboratório Interdisciplinar de Jogos Colaborativos, projeto de Extensão da Universidade Federal do Cariri - Ceará, neste campo de estudo. Nosso objetivo é o de apresentar, por meio de relato de experiência, o processo criativo que culminou na concepção do jogo colaborativo denominado CRIATIVA, apresentando as tomadas de decisão acerca do jogo e as relações com os conceitos estudados pelo grupo, bem como a metodologia do ciclo de produção de jogos educativos, concebida para e durante a criação deste jogo. 
A partir do exposto, pretendemos apresentar uma experiência inovadora, pautada em um método e técnicas capazes de contribuir com a produção de jogos cooperativos com finalidades educativa, tornando-se referência para profissionais da educação iniciarem seus estudos e possibilitar a contribuição destes atores, tanto no campo de estudos como para significar as relações educativas por meio de uma linguagem acessível.

\section{REVISÃO BIBLIOGRÁFICA}

Para iniciarmos a abordagem acerca do design de jogos, temos de compreender o que são jogos, qual a diferença entre jogos colaborativos e jogos competitivos, as questões de design abordando plataformas de jogo e sua importância no contexto da educação como forma de (re)significar as relações. Todas essas questões e conceitos formam a base para a construção da CRIATIVA.

Os jogos, para Cailois (1990) e Huizinga (2000), fazem parte da história da humanidade, enchendo de significado atividades lúdicas que são pensadas com uma vocação social, capazes de interação, com um sentido e contribuem para a socialização de temas e pessoas.

A design de jogos Mcgonial (2012), afirma que os jogos afetam a realidade de seus participantes pois oferecem: a) metas que geram um senso de objetivo claro, b) regras que estimulam os participantes a explorar criativamente possibilidades, c) trazem um sistema de feedback claro, que demonstram o progresso para se atingir a meta e d) tudo isso possibilitado por meio da participação voluntária.

Atingir satisfatoriamente estes pontos seria de difícil acesso metodológico, por isso, nos interessamos em jogos, digitais ou analógicos, e em atividades cooperativas por meio destes, visto que, os pontos apresentados são complexos a nossa realidade, mas quando oportunizados através destas atividades lúdicas provocam o que a psicologia positiva chama de fluxo, uma forma endógena de se produzir satisfação (Mcgonial, 2012), estando esta, inerente a proposta da atividade através da interação lúdica.

Os jogos cooperativos e competitivos têm a mesma estrutura: metas, regras, feedback e participação voluntária. Nos jogos competitivos a rivalidade gera uma onda que descaracteriza o ser humano quanto ser social, favorecendo uns em detrimento de outros, fortalecendo o individualismo e a racionalidade instrumental (Maturana, 2002). Joga-se para vencer os outros, joga-se para ser o melhor, excluindo o outro pelo processo, apresentando a vitória individual como resultado da ação. "A hipervalorização da competição se manifesta nos jogos por meio da ênfase no resultado numérico e na vitória" (Broto, 2013) o que nos leva a perceber o jogo competitivo como uma estrutura rígida, ao qual, o processo que o conduz é desinteressante, onde apenas o resultado importa.

Nos jogos cooperativos a situação se inverte. O processo é tão importante quanto o resultado, sua estrutura alternativa onde os participantes jogam uns com os outros, ao invés de uns contra os outros, estabelece o jogo cooperativo como uma atividade onde todos os participantes podem ter igual importância. Joga-se para superar desafios, joga-se por gostar do 
jogo e pela satisfação de joga-lo, nestes jogos o esforço cooperativo é a ferramenta para vencer, muito mais importante torna-se, portanto, reconhecer o outro como parceiro, que divide com você o mesmo interesse em um processo onde as pessoas se complementam. (Broto, 2013; Almeida, 2011, Almeida 2010)

Almeida (2010) complementa a ideia quando nos descreve que a finalidade dos jogos cooperativos é o brincar com o outro, o sucesso e o fracasso são compartilhados, todos fazemos parte do mesmo jogo. Essa ideia central da atividade cooperativa vem de encontro ao status quo, que apresenta a competição como a forma de resolução de situações problema através da geração de conflitos, criando uma massa de perdedores em prol de alguns poucos vencedores.

Estabelecemos, por meio dos jogos cooperativos, uma base comum ao pensamento de Freire $(1987,1996)$, sendo a educação estruturada por uma base dialógica, onde os atores do processo se encontram lado-a-lado, trabalhando em conjunto para criar os fundamentos necessários da ação pedagógica, entendendo que "ensinar não é transferir conhecimento, mas criar as possibilidades para a sua própria produção" (Freire, 1996).

Compreendemos que a educação se faz a partir da intercomunicação dos indivíduos que participam do processo, "Ninguém educa ninguém, ninguém educa a si mesmo, os homens se educam entre si, mediatizados pelo mundo" (Freire, 1987).

Essa metodologia educativa possibilita uma ação educativa horizontal, podendo-se transcender questões como a motivação para se aprender um conteúdo, aplicabilidade e a influência de uma "disciplina" apresentada no campo de estudos. Na prática, inter-relacionam-se os temas, conhecimentos, habilidades e processos com as características de interesse dos participantes, apresentada na proposta do jogo, o que vem a refletir em sua ontologia.

Para se dar origem a um jogo cooperativo, utilizamos ferramentas e conceitos apresentados pelo design de jogos ou game design, tendo em Schell (2011), Schuytema (2008) E Salen e Zimmerman (2012a, 2012b, 2012c e 2012d) nossas referências.

Para Schell (2011) o game design é o "ato de decidir o que um jogo deve ser", quais serão suas metas, suas regras, a forma que os participantes serão recompensados e de que forma eles participarão e irão interagir com o "mundo" do jogo a ser explorado.

Schuytema (2008) nos apresenta uma analogia, tendo o design de jogos como a planta baixa de um jogo, ou seja, a base com que este deve ser criado. A partir desta planta baixa são inseridos seus elementos construtivos, entre eles: A mensagem que um jogo deseja passar, sua função, a diversão como elemento importante de todo jogo e a plataforma (analógica ou eletrônica) utilizada como interface. Todos estes elementos são então inseridos na planta baixa, fomentando a ideia inicial através de um processo criativo que envolve, normalmente, uma equipe com diversos papéis.

Salen e Zimmerman (2012a, 2012b, 2012c e 2012d) exploram o conceito de design de jogos de forma dicotômica. Para eles o design é "o processo pelo qual um designer cria um contexto a ser encontrado por um participante, a partir do qual o significado emerge", significado este ligado 
ao conceito de semiótica, onde um signo pode representar algo diferente dele mesmo, este deve ser interpretados pelo participante tendo o contexto ao qual o símbolo é apresentado (o jogo) grande influência sobre sua interpretação, e a partir desta ação de interpretar, temos seu significado.

Os jogos, por sua vez, são o resultado das inter-relações entre o jogo e a interação lúdica, sendo o primeiro um sistema no qual os participantes se envolvem na resolução de situações problemas, proposto pelas regras e metas do jogo, que resultam em algo que possa ser valorado. O segundo, surge na relação entre o jogador e o desfecho do próprio jogo, de suas regras, onde só é significativa quando a relação entre as ações e os resultados são discerníveis e integradas ao contexto (Salen \& Zimmerman, 2012a, 2012b, 2012c e 2012d).

Desta forma, podemos sintetizar as ideias dos dois autores (Salen * \& Zimmerman, 2012a, 2012b, 2012c e 2012d) tendo o design de jogos como o processo de tomada de decisão pela qual o contexto do jogo toma significado por meio das ações executadas e pela forma que são interpretadas pelo participante. O processo criativo de organização dos símbolos e signos, interrelacionando as regras e o papel do participante é a função do design de jogos.

Com estes temas esclarecidos, tomemos agora parte no processo criativo de design de jogos utilizado para a concepção da metodologia educativa, perpassando o conceito de jogos cooperativos, que deu origem a CRIATIVA.

\section{METODOLOGIA}

Para compormos o presente estudo utilizamos de metodologia de pesquisa bibliográfica que "permite ao investigador a cobertura de uma gama de fenômenos muito mais ampla" (GIL, 1999) num aporte conceitual do objeto a ser estudado, compreendendo as ideias elaborados por diversos autores, a fim de identificar as estruturas apresentadas e os métodos explorados. Além disso, temos o caráter exploratório da pesquisa pois "busca [nesse artigo] levantar informações sobre um determinado objeto, delimitando assim um campo de trabalho" (SEVERINO, 2007) de forma a promover, descrever e relatar as informações empregadas no processo de concepção da CRIATIVA.

Organizamos o presente trabalho na forma de relato de experiência sobre esse processo criativo, descrevendo a experiência de concepção do jogo, ocorrida entre fevereiro e maio de 2015, pelo Laboratório Interdisciplinar de Jogos Colaborativos. Esse relato consiste na apresentação dos resultados, por meio de observação participante, onde registramos o exame do processo que conduziu as escolhas, e, para além disso, seus resultados sem prejulgamentos, com a finalidade de compreender os dados e seu contexto na pesquisa (MINAYO, 2013).

A partir dos resultados apresentados nessa experiência e de seu relacionamento com os conceitos abordados pelos diversos autores, apresentaremos nossa metodologia que sistematiza o processo de concepção do jogo. 


\section{RESULTADOS E DISCUSSÃO}

Deste ponto em diante discutiremos os aspectos de design de jogos que fomentaram a sua concepção, dialogando sobre o ambiente controlado propiciado pelo jogo, suas metas, regras, sistema de feedback e mecanismos de participação dos jogadores. O relato desse processo criativo tem o intuito de contribuir para a criação de outras metodologias do mesmo aporte, sendo um dos objetivos deste artigo.

\subsection{Ambiente controlado a partir do jogo cooperativo}

Propiciar aos participantes um ambiente controlado é a base para este jogo, escolhemos uma empresa de publicidade e propaganda, denominada CRIATIVA, como ambiente a ser utilizado para propor essa experiência ao jogador. Os participantes são parte desta empresa, esta é a planta baixa do jogo, sua base (Schuytema, 2008). Nesta base, podemos encontrar diversos serviços e produtos oferecidos por uma empresa, mas não estamos tratando de uma empresa real e sim de uma empresa fictícia, um símbolo, que, portanto, pode ser visto com diversos olhares e interpretações sob a ótica de cada participante, que traz conhecimentos prévios acerca do ambiente.

$\mathrm{Na}$ interpretação deste signo reside o interesse do participante em realizar as ações propostas pelo jogo, uma vez que ele aborda uma temática de realização de processos criativos sob pressão, este tem a possibilidade de imergir no ambiente controlado, onde os jogadores constroem um conhecimento coletivo, através da dialógica, demonstrando seu ponto de vista e aprendendo de forma cooperativa ao captar as impressões dos seus companheiros sobre estes signos e suas interpretações pessoais.

Essa é uma decisão de design de jogo, que influencia a forma como serão geridos os processos que o conduzem, suas metas, regras, feedback e forma de participação. Tomamos como base, nesta escolha, o questionamento que nos é apresentado por Freire (1996), "Por quer não estabelecer uma necessária "intimidade" entre os saberes curriculares fundamentais aos alunos e a experiência social que eles têm como indivíduos?" Estando para além das questões de design de jogos, tomamos esta decisão, por pensar o ambiente de jogo como uma possibilidade de utilizar estes conhecimentos e habilidades já comuns ao público, como o pintar e o desenhar, escrever e relatar, administração financeira e estratégica de recursos, a geometria associada ao conhecimento das cores na construção de um produto, conhecimentos de estética e do próprio material a ser utilizado, a estratégia produtiva e o diálogo que fomentam o processo criativo. Tudo isso reconhecendo nos participantes o desejo de utilizar, de forma criativa, estes pontos, que seriam de difícil uso em situações cotidianas.

Nesse ambiente controlado o facilitador (papel que cabe ao coordenador do jogo, seja ele um professor ou estudante) pode explorar estes conhecimentos e habilidades, relacionando todo esse conteúdo com o signo proposto no ambiente. Inter-relacionando essas esferas propiciamos um ambiente criativo necessário a resolução de problemas que serão propostos pelas metas e regras do jogo de forma conjunta. 


\subsection{Metas do jogo}

Os objetivos são escolhidos de acordo com o ambiente. Para se jogar este jogo os participantes devem ser colaboradores da CRIATIVA, assim, tomamos como base o pensamento comum do objetivo de uma empresa, a busca pelo lucro máximo. Realizando serviços e criando produtos, a empresa é recompensada financeiramente. Quanto maior a qualidade e a aceitação destes produtos e serviço, maior é seu reconhecimento.

Tenha em mente que o papel da meta é o "resultado especifico que os jogadores vão trabalhar para conseguir. Ela foca a atenção e orienta continuamente a participação deles ao longo do jogo" (Mcgonial, 2012). Esta deve estar sempre clara aos jogadores, é o objetivo do jogo, mesmo não sendo a finalidade ao se aplicar um jogo cooperativo, é importante, pois gera um senso de objetivo.

Para darmos lugar a estas ideias, criamos uma moeda, a moeda CRIATIVA. Um valor monetário fictício que serve como pagamento dos trabalhos realizados com sucesso, pagamento de multas contratuais e também é utilizada pelos participantes na compra de materiais diversos que compõem seus produtos. Ela representa o lucro da empresa.

O primeiro objetivo do jogo é o lucro, terminar o jogo com mais dinheiro do que se iniciou. Para isso, num primeiro momento, entregamos a todos os participantes uma unidade de moeda CRIATIVA, explicando que este é o dinheiro da empresa, e pedimos que todos depositem esse dinheiro no caixa (que pode ser um pote plástico ou mesmo uma caixa de sapatos) que é posicionado no meio da sala para que todos tenham acesso.

O outro objetivo do jogo é o de realizar serviços e/ou criar produtos, que serão utilizados para se arrecadar o dinheiro que "alimenta" o caixa. A segunda ferramenta que criamos para o jogo é o BRIEFING, um documento que apresenta aos jogadores o possível serviço que eles serão contratados para realizar, explicando o que se deve criar, o histórico do contratante, suas cores e logotipo; a visão e a meta do contratante.

Cada BRIEFING apresenta aos jogadores um tempo, a recompensa por realizar o produto com sucesso e também uma multa (caso estes desejem abandonar um projeto), valor que será subtraído imediatamente do caixa da empresa. Nesta mesma peça temos uma ficha de avaliação, que serve para o facilitador "julgar" o item criado pelo grupo, que pode ser um sucesso (Ihes rendendo a recompensa), um fracasso (onde vão perder apenas tempo e material investido) ou a opção de voltar para a prancheta (onde os participantes têm um tempo extra para tentar finalizar a atividade). Buscando facilitar a realização da tarefa, cada BRIEFING também traz material adicional que os participantes recebem ao escolher resolver aquele problema.

O jogo é dividido em grupos, como veremos no próximo ponto, e a meta é que cada grupo realize, ao menos, o trabalho requerido em um BRIEFING com sucesso. Criamos um pacote básico com dez tarefas que envolvem desde a criação de logotipo, cartaz, folder de evento, slogan, comercial para TV, comercial para rádio, e cartão de visitas. Estes serviços requerem a utilização da criatividade e um relacionamento interdisciplinar de conhecimentos como já apontado quando tratamos do ambiente. 
Notemos que estas duas metas interligam todo o contexto de significados explorado na CRIATIVA, o que não poderia ser diferente, já que, de acordo com o ambiente controlado, estas são razões de existir para uma empresa. Ambas são percebidas como metas globais, onde todos juntos jogam para supera-las.

\subsection{Regras do jogo}

As regras são as diretrizes norteadoras do jogo, que são postas para limitar a forma como as atividades deverão ser realizadas, entre elas já observamos o tempo para a realização dos processos criativos, o gerenciamento de recursos por meio da moeda CRIATIVA e a multa, caso os jogadores desejem desistir da realização de uma atividade.

Tenha em mente que as regras

"impõem limitações em como os jogadores podem atingir a meta. Removendo ou limitando as maneiras óbvias, as regras estimulam os jogadores a explorarem as possibilidades anteriormente desconhecidas para atingir o objetivo final. Elas liberam a criatividade e estimulam o pensamento estratégico" (Mcgonial, 2012).

Não sendo, portanto, formas de punir os participantes, mas sim de auxilia-los nessa jornada em busca da construção e (re)significação de conhecimentos e habilidades, estimulando a criatividade. Agora, veremos algumas outras regras ou mecânicas do jogo.

Os participantes são divididos em grupos de cinco membros, onde cada um tem um papel determinado, sendo o conjunto dos jogadores denominado de grupo-classe. Esta divisão visa organizar os participantes e estruturar a metodologia, para isso utilizamos a teoria de jigsaw apresentada por Aronson (In Almeida, 2011) e revisitada por Slavin (In Almeida, 2011), que tem como características: a) O facilitador explica o problema proposto na atividade, b) formam-se grupo heterogêneos, c) dentro de cada grupo são estabelecidos papéis e e) os membros tem a chance de atuar nos distintos papéis.

A formação de grupos heterógenos em etnia, sexo e idade evita que os participantes que tem mais afinidade trabalhem em conjunto, dando oportunidade aos jogadores de conhecer diferentes pessoas e opiniões, isso é o que acontece realmente em uma empresa, não podemos escolher nossos colegas de trabalho. Os papéis ajudam os jogadores a realizar as tarefas, dando um maior sentido e organização a atividade, sendo estes baseados no ambiente escolhido. São eles: a) Contador de tempo: 0 jogador que cronometra o tempo auxilia o grupo para que o trabalho seja realizado no período correto, b) mediador: Tem o papel de percorrer os grupos para dialogar, tirar dúvidas e expor as ideias de um grupo ao grupo-classe, tornando o jogo mais organizado e fluído, c) tesoureiro: Ele arrecada os recursos e o gerencia, junto com todos os tesoureiros dos outros grupos, realizando o controle das finanças da empresa, d) apresentador: Responsável por apresentar ao facilitador o produto final, tentando convencer de que este deve ser aprovado e e) relator: Este jogador realizará anotações acerca de como se deu o processo criativo e a participação dos jogadores e suas contribuições e ideias, que serão relatadas no fim do 
jogo. Este relato é uma pré-avaliação do jogo expondo os momentos e as relações dentro de cada grupo.

Com os papéis explicados, os grupos já divididos devem entrar em consenso sobre o papel que cada membro irá desempenhar, caso o grupo seja composto por mais componentes, eles devem repetir um papel ou caso contrário omitir um papel. O ideal para o formato da metodologia educativa em sua aplicação é o de cinco integrantes por grupo. Essa divisão de tarefas é utilizada para que os jogadores tenham noção de como podem participar da atividade, o que evita a dispersão do participante e facilita o trabalho em grupo.

Mais duas regras complementam a CRIATIVA, são elas o uso de ferramentas e aquisição de materiais. Durante o processo criativo, os participantes poderão adquirir materiais comprados com moeda CRIATIVA, a fim de realizar suas tarefas, estes materiais podem ser: Lápis, caneta, pincel, marcador de texto, lápis de cor, giz de cera, borracha, tinta acrílica, revistas e jornais para recortar, folhas de papel em diversos tamanhos, cores e formatos; fitas coloridas, botões, sementes e folhas, flores, tecidos diversos.

Na mecânica do jogo os participantes terão de gerenciar seus recursos para comprar essas matérias de acordo com as situações problema a serem resolvidas. Assim, se um grupo escolheu criar um cartaz, ele terá de adquirir folha de papel, lápis e tintas, por exemplo, para criar o produto tendo o cuidado de pensar estrategicamente para que estes recursos não custem ao grupo-classe, mais moeda CRIATIVA do que eles serão recompensados pela atividade.

Uma vez adquirido o material ele é de todo o grupo-classe e deve ser compartilhado, já que para sua aquisição, uma decisão conjunta (realizada geralmente pelos tesoureiros) deve ser tomada.

As ferramentas que são utilizadas em conjunto com os materiais são gratuitas, no entanto, devem ser racionadas, já que são colocadas em quantidade inferior à dos grupos. Ferramentas são: Tesouras, cola, régua, pinceis, apontador, potes para misturar tintas, transferidor e compasso, por exemplo, assim, se temos 4 grupos, podemos optar por ter entre um e dois exemplares de cada uma destas ferramentas. Dessa forma os membros dos grupos terão de gerenciar seu uso, de forma dialógica, para que cada um dos grupos possa utiliza-las sem prejuízo para que o grupoclasse atinja os objetivos do jogo.

\subsection{Sistema de feedback}

Feedback apresenta as respostas do jogo as ações dos jogadores, dois feedbacks são importantes para se alcançar a vitória no jogo, estes já foram explicados nas metas do jogo. Cabenos agora explicar o feedback contínuo durante o jogo que será dado através da avaliação dos BREAFINGS.

Quando um trabalho é terminado o jogador que faz o papel do apresentador do grupo deve convencer o facilitador, que interpretará o papel de cliente, que este trabalho está finalizado sendo o melhor para aquele cliente. No BREAFING existe uma ficha de avaliação, com os principais 
requisitos feitos pelo cliente e durante a conversa o avaliador deve preencher a avaliação proposta e apresentar um entre três resultados: Aprovado, reprovado ou de volta a prancheta.

Esse sistema de feedback continuo possibilita um acompanhamento do progresso da atividade por parte do facilitador e dos jogadores, que irão saber o quanto eles estão próximos ou distantes da vitória no jogo (Mcgonial, 2012). O feedback continuo é importante pois pode mudar a estratégia do grupo-classe de acordo com seus resultados.

\subsection{A participação voluntária}

Uma condição para participar da aplicação do jogo está em aceitar as metas, o sistema de regras e a forma com que o feedback será realizado, "isso estabelece uma base comum para as múltiplas pessoas jogarem o mesmo jogo" (Mcgonial, 2012), tendo estes a liberdade para entrar e sair do jogo a hora que desejarem, assegurando aos participantes o princípio voluntário de participar.

Por meio da participação voluntária construímos um sentimento democrático entre os participantes, que unem forças para resolver situações propostas pelo jogo, "problemas que ao indivíduo parecem insolúveis se contar só com suas próprias forças" (Boardenave, 1983, p. 12), mas que em grupo, tornam-se menores e menos dificultosos.

Para compreendermos as possibilidades dessa participação, analisemos a frase de BOARDENAVE (1983): "Participação é fazer parte, tomar parte ou ter parte". Note a clareza dos verbos fazer, tomar e ter; eles são importantes quando buscamos compreender de que forma pode-se entender essa conceituação.

Fazer parte de algo, como por exemplo um jogo cooperativo, demonstra que existe uma relação entre o conjunto e o participante, no entanto, não requerer uma integração, um sentimento para com o que se faz parte, o que nos levaria a pensar a participação de forma passiva por parte do sujeito da ação. Tomar parte significa trazer para si responsabilidades, e se você toma parte dos problemas apresentados no jogo, tentando resolve-los, automaticamente estará interagindo com um todo, um sistema complexo onde pessoas e ideias interdependentes, sendo uma atitude ativa do sujeito da ação. Por fim, ter parte está ligado ao sentimento de direito participativo que marca a ação do sujeito, ter parte no jogo, é a ação voluntária provocada pelo sentimento de direito e dever na resolução do problema, é estritamente pessoal (BOARDENAVE, 1983).

\subsection{Ciclo criativo de produção de jogos educativos}

Todos estes pontos fazem parte do processo criativo de tomada de decisão para a construção da metodologia educativa. Tomamos estas decisões baseados nos estudos dos autores Mcgonial (2012), Schuytema (2008), Salen E Zimmerman (2012a, 2012b, 2012c E 2012d) E Schell (2011). Para organizar e estruturar esta metodologia criamos, a partir deste referencial, um ciclo 
"criativo de produção de jogos educativos", tendo nos servido de diretrizes e organizado os passos da tomada de decisão. Essa metodologia é ilustrada na figura abaixo:

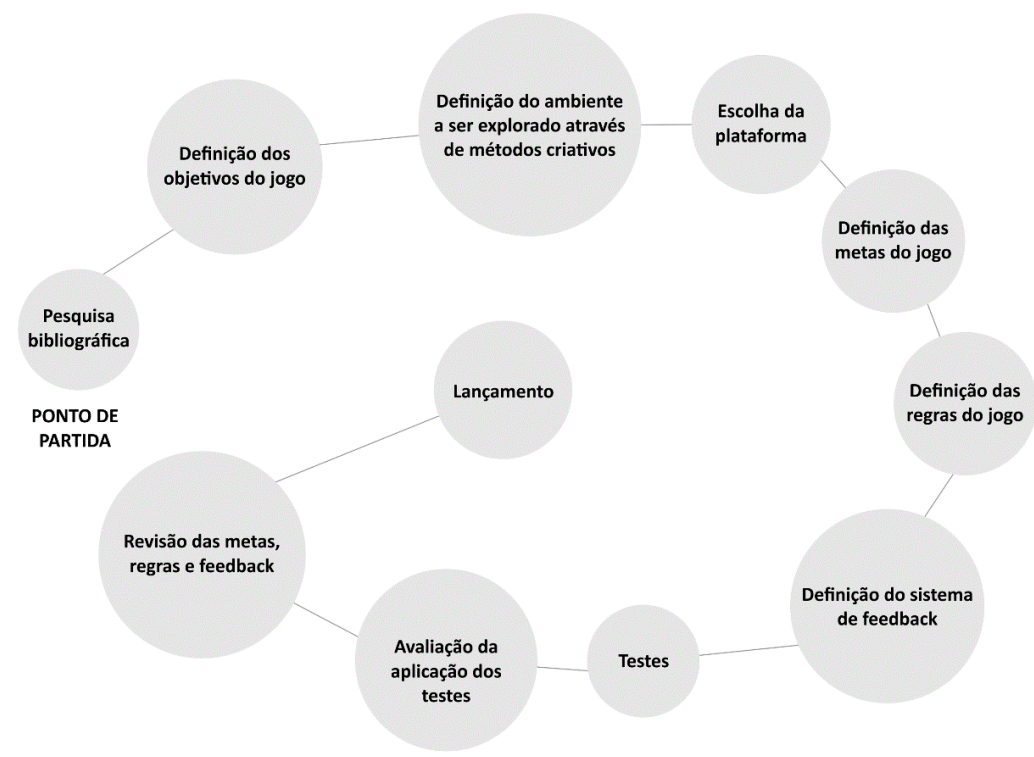

Figura 1 - Ilustração da metodologia do ciclo de produção de jogos educativos

Baseados nessa metodologia, organizamos o processo criativo tendo em vista que todas estas fases do ciclo são complementares, não-lineares, sendo diretrizes e não regras a serem cumpridas de forma restritiva.

Iniciamos realizando a pesquisa bibliográfica acerca do design do jogo e dos possíveis temas, definimos então quais seriam os objetivos do jogo, qual a experiência que o jogador vai ter ao participar da atividade e de que forma desejamos trabalhar.

Para escolher o ambiente ao qual desenvolveremos o jogo utilizamos a metodologia design thinking em conjunto de mapas conceituais (por meio do software XMind6) relacionando as ideias dos participantes e seus conhecimentos prévios sobre o assunto, o que contribui para um tomada de decisão interdisciplinar, já que a pluralidade de participantes fomentou a confecção do jogo.

Optamos por criar um jogo analógico, que utiliza apenas textos básicos e materiais, optando por uma ferramenta de baixo custo que não necessita de grandes habilidades para reunir uma turma e ser aplicada, apenas a leitura de um manual de regras é suficiente, tornando o jogo mais prático e acessível.

Baseados no ambiente, retornamos a pesquisa bibliográfica todo o tempo, agora para obter informações sobre o tema escolhido. Transformamos essas informações em metas, regras e um possível sistema de feedback do jogo. O que aproxima o processo a realidade que desejamos experimentar, propiciando que o ambiente controlado seja o mais próximo possível (em significados e conceitos) do ambiente real.

Para auxiliar o processo criativo recomendamos que a todo momento os participantes procurem jogos e experiências lúdicas para se divertir com o grupo, buscando interações através 
dos jogos para conhecer novas mecânicas, sistemas de feedback e formas de participação. Se você deseja criar um jogo, nada melhor que jogar vários jogos, poder obter conhecimento nesse campo através de várias e significativas experiências.

Com o primeiro escopo do jogo em mãos, escrito por meio de um manual, aplicamos o jogo em sua versão inicial. Observamos se as regras são conflituosas, se as metas são de fácil ou difícil acesso pelos jogadores, se o sistema de feedback os mantém motivados, se e como os participantes estão se divertindo e participando. No caso da CRIATIVA utilizamos um questionário qualiquantitativo, através da metodologia do discurso do sujeito coletivo (LEFEVRE; LEFEVRE, 2012), apresentando esses dados a todos os envolvidos na concepção do jogo, para avaliarmos se o jogo atingiu seus objetivos.

Após avaliarmos o primeiro escopo, o jogo deve ser completamente revisado. Tomando como base os dados da primeira aplicação, novas mecânicas podem ser adicionadas e outras retiradas, e novos testes devem ser feitos de forma gerar novas avaliações e revisões. Esta fase do ciclo: Teste, avaliação da aplicação do teste e revisão das metas, regras e feedback; consomem o maior tempo de produção, sendo a parte mais importante e só culminando no lançamento do jogo quando o grupo sentir que os objetivos do jogo são plenamente alcançados pelos participantes.

Bons jogos são criados por meio de testes, o chamado playtest. Este momento é extremamente necessário, pois alerta a equipe de produção criativa sobre problemas que podem ser resolvidos, verificando se o jogo fomenta a experiência a qual foi criado (SCHELL, 2011).

Este ciclo nasce de estudos bibliográficos e da experiência de concepção da CRIATIVA, chegando a ser simplória se pensarmos nas ricas experiências de famosos game designers, no entanto, o objetivo deste ciclo não é o de criar uma ferramenta para designers experientes, mas o de apresentar um arquétipo que pode ser utilizado por docentes, discentes e entusiastas por novas e instigantes metodologias, para a produção de jogos educativos que possam (re)significar relações educativas.

\section{CONCLUSÃO}

O aporte bibliográfico foi fundamental para o processo criativo, influenciando tanto a metodologia do ciclo de produção de jogos educativos, como a definição do ambiente e o "estilo cooperativo" do jogo. Os estudos realizados pelos membros do Laboratório Interdisciplinar de Jogos Cooperativos permeiam todo o trabalho, comprovando que a estruturação de uma metodologia deve ser criteriosa e recheada de conceitos sobre os temas.

A concepção da CRIATIVA foi uma experiência interdisciplinar que exigiu tempo, pensamento criativo, pro-atividade e uma equipe bem estruturada, itens fundamentais a produção de qualquer produto ou serviço. As escolhas metodológicas (jigsaw, design thinking, mapa conceitual e discurso do sujeito coletivo) nos ajudaram a estruturar tanto o formato do jogo como a própria metodologia do processo criativo, todo o contexto do jogo está inter-relacionado, influenciando e sendo influenciado pelas metodologias utilizadas. 
Outro aspecto de fundamental importância foi a oportunidade de reunir a equipe para conhecer diversos jogos comerciais, cooperativos e/ou competitivos, conhecendo novas mecânicas, sistemas de feedback e metas. Esta atitude não é meramente um momento de entretenimento da equipe, mas consiste em um aporte empírico, onde o pesquisador/design de jogos tem a possibilidade de obter visões diferentes acerca do tema deste artigo, reconhecendo no trabalho de outros designers de jogos, métodos e técnicas que influenciam diretamente o processo criativo.

Devemos lembrar que todos os passos na metodologia apresentada se inter-relacionam, podem e devem ser alterados de acordo com a planta baixa. O método é seu aliado e não uma camisa de força ou mesmo uma muleta. O mesmo vale para as regras do jogo, elas devem proporcionar desafios que façam com que os participantes lidem criativamente com situações problema, não sendo concebidas para engessar o jogo.

Buscamos contribuir com o campo de estudos das metodologias educativas através dos jogos cooperativos, apresentando um relato de experiência sobre o processo criativo que originou a metodologia CRIATIVA, bem como o método que guiou este processo e sua equipe, sendo este possível de adaptação para qualquer projeto de extensão, ensino ou mesmo pesquisa, que deseje tratar do tema de design de jogos voltado a educação.

Este artigo conta com o material produzido nas fases de pesquisa bibliográfica, definição dos objetivos do jogo, definição do ambiente a ser explorado através de métodos criativos, escolha da plataforma, definição das metas do jogo, definição das regras do jogo, definição do sistema de feedback e teste (primeira rodada de testes), faltando apenas avaliarmos a aplicação deste teste, revisar as metas, regras e feedback; para então realizarmos um segundo teste e provavelmente realizarmos uma nova avaliação e um terceiro teste, que pode possibilitar o lançamento da ferramenta.

Contudo, para estudos futuros, pretendemos apresentar os resultados deste primeiro teste, que foi realizado com estudantes da Universidade Federal do Cariri, Universidade Regional do Cariri e Universidade Estadual do Vale do Acaraú - Campus Crato, onde obtivemos a participação de 44 pessoas, bem como possíveis reformulações no sistema de regras, das metas e do sistema de feedback.

\section{REFERÊNCIAS}

ALMEIDA, Marcos Teodorico Pinheiro de. (2010). Brincar Cooperativo: Vivências lúdicas de jogos não competitivos. Petrópolis, Rio de Janeiro: Vozes.

ALMEIDA, Marcos Teodorico Pinheiro de. (2011) Jogos Cooperativos: Aprendizagens, métodos e práticas. Várzea Paulista, São Paulo: Fontoura.

BOAVENTURA, de Sousa Santos. (2006) Um discurso sobre as ciências. São Paulo: Editora Cortez, 4a Edição, 2006.

BORDENAVE, Juan E. Diaz. (1983). O que é participação? São Paulo, SP: Editora Brasiliense. 
BROTTO, Fábio Otuzi. (2013) Jogos Cooperativos: O jogo e o esporte como um exercício de convivência. São Paulo, SP: Palas Athenas, 4ạ Edição.

CAILOIS, Roger. (1990). Os jogos e os homens. Lisboa - Portugal: Editora Cotovia.

FREIRE, Paulo (1996). Pedagogia da autonomia: Saberes necessários à prática educativa. São Paulo: Editora Paz e Terra, 24a Edição. . (1987) Pedagogia do oprimido São Paulo: Editora Paz e Terra, 11a Edição.

GIL, Antonio Carlos. (1999). Métodos e técnicas de pesquisa social. São Paulo - SP: Atlas, 5a ed.

HUIZINGA, Johan. Homo Ludens. (2000). São Paulo - SP: Editora Perspectiva S. A.

LEFEVRE, Ana Maria; LEFEVRE, Fernando. (2012). Pesquisa de representação social: Um enfoque qualiquantitativo. Brasilia - DF: Liber Livro, 2ed.

MATURANA, Humberto. (2002). Emoções e linguagem na educação e na política. Belo Horizonte: UFMG.

MCGONIAL, Jane. (2012). A realidade em jogo: Por que os games nos tornam melhores e como eles podem mudar o mundo. Rio de Janeiro, RJ: Editora Bestseller.

MINAYO, Maria Cecília de Souza. (2013). Pesquisa Social: Teoria, método e criatividade. Petrópolis - RJ: Editora Vozes, 33ed.

SALEN, Katie; ZIMMERMAN, Eric. (2012a). Regras do jogo: Fundamentos do design de jogos. São Paulo - SP: Blucher. Volume 1. Paulo - SP: Blucher. Volume 2.

(2012b). Regras do jogo: Fundamentos do design de jogos. São (2012c). Regras do jogo: Fundamentos do design de jogos. São Paulo-SP: Blucher. Volume 3.

(2012d). Regras do jogo: Fundamentos do design de jogos. São Paulo - SP: Blucher. Volume 4.

SCHELL, Jesse. (2011). A arte de game design: O livro original. Rio de Janeiro - RJ: Elsevier.

SCHUYTEMA, Paul. (2011). Design de Games: Uma abordagem prática. São Paulo - SP: Cengage Learning.

SEVERINO, Joaquim. (2007). Metodologia do Trabalho Cientifico. São Paulo - SP: Editora Cortez, $23 e d$. 